\section{SOCIOLOGIC REFORMS.}

Opening address, read before the State Conference of Charities and Corrections at Springfield, Nov., 12, 1896.

BY ARTHUR R. REYNOLDS, M.D.

PRESIDENT OF THE BOARD OF STATE COMMISSIONERS OF PUBLIC CHARITIES OF ILLINOIS.

The Board of State Commissioners of Public Charities were moved to call this conference, feeling that there was a growing demand for knowledge of our institutions, and an increasing interest in the care of dependent persons. There seems, also, to be an awakening among charitably inclined people, as to how best to help those who can not help themselves. It is true, that our board publishes every two years a report of their doings, so also do the larger institutions, but they are read by comparatively few persons.

The amount of money paid out directly by the State, to support persons unfitted by nature or disease to support themselves, is very large, but when we come to consider the amount expended by the several counties und municipalities, and the sums subscribed, through churches and other public bodies of organized charity, together with the amount expended in private work. of the same kind, the total amounts to enormous figures.

It is to the credit of the tax-payers that there is never any complaint against paying a liberal allowance for the care of the sick and needy, and however heavy the total burden of taxes may be, there is no one that would have it lightened, if the retrenchment would bear upon the scanty portion of the poor.

Notwithstanding all the treasure that has been lavished upon the unfortunate, there seems to be an increasing demand that it should go on and on. There are many indications to warrant the belief that the increase of dependents is in greater proportion than the increase of population. In spite of the efforts made toward relief, the increase of those who need care grows faster than the increase of the means to care for them. Some even go so far as to say the race is in danger of being overwhelmed, and fear for the future of the State and society.

As we ponder on the subject, the conviction grows that there is something wrong in our methods of dealing with the question. We ask ourselves whether or not it be wise to continue forever harvesting this crop of human tares; if it would not be wiser to follow the example of the prudent husbandman, and prevent the unprofitable seed from taking root: if it would not be wiser still to expend more time and toil preparing the soil for the sowing, that there may be economy in the gleaning.

We can not escape the fact that a large number of criminals and those with a susceptibility to mental and physical disease, and even the paupers, are fore. doomed to their fate before they are born, and should not have been born at all.

It may not be practicable for an officer of the State to sit in judgment upon those who would marry, and properly foretell the exact physical and mental mold of the progeny. The State, however, can and should be able to do as much for the breeding of men and women as is done for the breeding of the beasts of the field. The passage of a just law for the regulation of marriage, with skilled officers to enforce it. would call the attention of the public to the question mostforcibly. Once it becomes a matter of serious thought and study, by the people, the cure will be near at hand. There are none but would recoil from the thought of begetting offspring that would be lacking in any respect, if the question were brought home by a law that required them to pass muster before competent authority. While I firmly believe in proper selection for marriage I do not think this is the whole evil. More criminals, paupers and dependents generally are made after they are born than before. The children of vicious parents can be trained in the ways of righteousness if the training begin at the cradle, and the child of the good and wise can be spoiled if trained by vicious and indolent hands. We need more kindergartens and social settlements for the babies in the congested tenement districts of cities, before we add more universities for adults. If we can for one generation give to all children the proper environment and judicious training, we will have less need for penitentiaries, jails, bridewells, police stations and criminal courts. Indeed, such training is even a most rational cure for the withering blight of inebriety, and the endless train of degenerating evils, that follows in its wake.

If the proper training of children is of such moment, the greatest protection must be thrown around the sanctity of the home, for it is in the home and only in the home that the very best training can be had. The home, to be sacred, must be segregated, for indiscriminate crowding and association develops the evil propensities of a child rather than the good. Nowhere can the homes of the poorer people be segregated so well as in the country. Orphan asylums may be necessary and the right thing in their way for the present, but they are at best but a makeshift for the real remedy. The children of today will be the home builders of tomorrow. A child raised in a public institution learns nothing of this art, and will not take kindly to it after leaving the institution. If the money spent in the support of orphan asylums were used to find individual permanent homes among the farmers for dependent children, in the great majority of cases a robust and normal adult would be the result. The direct saving of money, if this were the rule, must be great, and the gain to the State by improving the chances of the descendants is beyond estimate.

In our day the almighty dollar is the magnet that draws all mankind. To possess it is a passion with almost all kinds and conditions of men. It holds a despot's sway in the heart of every man, whether he be high or low in society's scale. It is a powerful entity that must be reckoned with in sociological science. So strongly developed is the desire for money, and the power it brings, and so keen is the struggle to obtain it, that rest, food, raiment, honor and even life itself are sacrificed on its altar.

Men crowd into a decade the labor that should be spread over the three score years and ten. Men and women suffering constantly from overwork and nervous strain can not reasonably be expected to beget children that are robust and normal, yet the world marvels that so few of the great have offspring that can fill the parent's sphere in the world. We are too apt to forget the fact that our men with the greatest minds and the strongest bodies have been reared almost wholly in the country.

The drift of population of late years has been toward the cities and away from the country. Efforts should be made to stop it, and transplant the surplus population of cities on the broad acres. But if we are to move the surplus out from the cities to the 
country, our wise men must, if they can, make the dollar as easy to obtain in the country, as it is in the city, for the possession of money is the goal that all are striving to reach. Those economic features that best foster the profit of the farm, then, must play an important part in the welfare of the race, and should be carefully considered by our statesmen, as well as by students of sociology.

The State of Illinois has established, under supervision of the Board of State Commissioners of Public Charities, fourteen institutions, caring for more than 12,500 persons annually at a cost of about $\$ 133$ per year each. Four of these are hospitals for the insane, affording care and treatment to 4,600 males and 3,000 females. Two other hospitals for the insane are in course of construction, one at Rock Island to accommodate 600, and one at Peoria to accommodate 200.

There are still about 1,000 insane in poorhouses, and in jails of the various counties, while Cook County maintains an insane hospital for the accommodation of about 1,300; there is also an asylum for insane criminals with 125 inmates; the Eye and Ear Infirmary with about 150 patients; the Industrial Home for the Blind, with about 75 inmates, who are furnished an opportunity to earn a portion of their living at least, and are freed from the feeling of utter dependence. There is a home for feeble minded children, with over 600 inmates, and as many more on the outside who should have the care of a similar home. The Soldiers and Sailors Home with 1,300 inmates; the Soldiers' Orphans Home, with 400 and over; the Home for Soldiers' widows with 20 inmates; the the school for the blind, with 150 pupils; the school for the deaf and dumb, with over 300 pupils; the home for juvenile female offenders, with 75 inmates.

The management of all the State's institutions in the humane, scientific and financial aspect, is well abreast of the times. In addition to the supervision of the State institutions mentioned, the Commissioners of Public Charities are commanded to visit "each of the poor houses, or other places where the insane may be confined at least once each year." There are 102 counties in the State, each of which has a poorhouse. To do all this work and do it well, requires almost the entire time of all five commissioners. The State asks that this service be rendered without salary, the State only paying the actual cash outlay made.

There is a pressing need for a Home for Epileptics, and this conference would do well to ask our Legislators to provide it. To my mind, the greatest need of all, is another well equipped home, capable of receiving all the feeble minded children in the State, where those capable of receiving instruction may be made in some degree useful, and where the others can have ample custodial care, and where all, as they grow older, can be so segregated that they will not leave any descendants to inherit the blight that makes them a reproach to our civilization.

I venture to suggest the propriety of so enlarging the scope of our State Board of Health, as will permit it to do at least as much for the development of man as is now being done for the development of dumb brutes. The Board of Health will not have reached its limit in sanitation till it will have prevented human beings from being born with a susceptibilty that invites the attack of the deadly disease germs. The first necessity of human beings is good health. It is not enough that a State Board of Health should point out the way to the individual, so he can avoid contact with a germ that may eat him up. It could, if it would, point out the way to develop a being so vigorous and so strong, that the dreadful germ will itself be destroyed in the contest. Perbaps, too, our higher educational institutions might enlarge their usefulness if they would add to their curriculum of study a year at the forge, the lathe, the work-bench, the loom, or even a year on a farm doing the routine duty of the hired man, and working from sun-up till the darkness drives him from the field. A thorough grounding in the duties of the farm is to learn the foundation of all industries. Indeed, I pity the man who knows nothing of rural life; he is seriously handicapped, no matter into what sphere his fate may lead him. It is on the farm that a young man can better than anywhere develop a strong body, and a robust and normal intellect. It is there that a ruggedness of character can best be developed, that will later on make him spurn an evening at the clubover wine and tobacco, where ribald jest is mistaken for humor. It will make him shun such perverted pastimes that too often lead to a degeneracy of his descendants.

Perhaps, too, such institutions of learning might with profit teach in a more practical way the physiology of man, to the end that none of their graduates would ever append their signatures to a document certifying to the wonderful virtues of Dr. Balsam's liniment. It is but fair that they should learn enough on the subject to drive out of them any superstitious notions they may have upon the cause and treatment of disease, for, "the proper study of mankind is man."

In conclusion, I beg to suggest the need of this conference, making a permanent organization and meeting at least annually to study the great problems that are embraced in the broad field before us. I can not think that the philanthropic spirit - the practical logic of the students of social law-the public spirit of the great commonwealth of Illinois, will be behind other States in this respect. She will take her place in this, as she has in so many other things, having no competitors but leading all, in the fullness of her destiny.

\section{WHO WAS THE FIRST TO ILLUMINATE THE SIGMOID CAVITY?}

Read in the Section ou Surgery and Anatomy, at the Forty-seventh Annual Meeting of the American Medical Association held at Atlanta. Ga., May 5-8, 1896 .

BY J. G. CARPENTER, M.D.

STANFORD, KY.

At Winchester, Ky., June, 1886, the author read a paper before the Kentucky State Medical Society on ulceration of the sigmoid cavity-Inversion of Trunk, Electric and Reflected Light in Diagnosis and Treatment, which was published in the American Practitioner and Neus, Vol. 11. New Series, No. 17, August 21, 1886, at Louisville, $\mathrm{Ky}$.

On November 30,1885 , the writer visited J- Mc. at Crab Orchard, Ky., who had had an attack of acute dysentery in August, 1885, and had made an incomplete recovery, and had been treated by his physician for chronic dysentery from September 18 to November of that year. Age of patient was 20 years, good family history, former health good, habits and morals good, and the following general and local conditions. existed, viz.:

The patient was pale, weak and anemic; the tongue had a yellowish-white coat; the bowels were tympan. 